\title{
Implementation of Single Phase Multimode Matrix AC-DC Converter
}

\author{
Sanjay Mohite, Suchitra Khoje
}

\begin{abstract}
This paper proposes a novel topology of multimode matrix AC-DC converter which gives multiple DC outputs using a single AC input. The generated multiple outputs appearing across load has both polarity (Positive and negative DC voltages). The control scheme developed for this converter is consisting of Op_Amps and AND gates and IGBTs are used as power devices. The multiple dc output are synthesized using sinusoidal pulse width modulation technique. A prototype model of proposed converter has been implemented and resultant voltage and current waveforms are analyzed. It has been observed that experimental and simulation results are promising for industrial applications with variable voltage.
\end{abstract}

Keywords: Multimode matrix AC-DC converter, Multiple output, power factor, SPWM,

\section{INTRODUCTION}

Traditionally, AC-DC converters are widely used in power supplies. AC-DC converters can be used as stand-alone application or can be used in multiple applications by connecting them in parallel. The cost and complexity could be more, when they are used in parallel combination for multiple applications. Multimode matrix AC-DC converter is developed for Multiple DC outputs with a single AC input. This system is cheaper as compared to traditional converters. The main feature of this converter is that it gives positive as well as negative DC voltage across loads as per the performance of multimode matrix AC - DC converter, they are now useful in industries because of. They have been well established as required by industry standard. Single stage, single switch AC-DC converters with isolated electrical output are available. As current state of art, lot many publications based Matrix Conversion are available. Performance of converter is improved using the utilization of switched-capacitor network [1]. By inverting the reference of AC current, reversible step up or step down AC-DC converter and DC-AC converters are implemented [2]. An AC-DC pulse width modulation PWM converter performing isolated dc-dc conversion are presented [3] which improves power factor. Transformer less AC-DC and DC-AC converter with

Revised Manuscript Received on October 30, 2019.

* Correspondence Author

Sanjay Mohite*, Sanjay Mohite, department of Electronics and Telecommunication, Jaywantrao Swant College of Engineering, Savitribai

Suchitra Khoje*, School of Electronics and Communication engineering, MIT World Peace University, Pune, India.. Email: suchiamol08@gmail.com

(C) The Authors. Published by Blue Eyes Intelligence Engineering and Sciences Publication (BEIESP). This is an open access article under the CC BY-NC-ND license (http://creativecommons.org/licenses/by-nc-nd/4.0/) requirement. Due to the properties, characteristics and better Phule Pune University, Pune, India. Email: sb.mohite@gmail.com

diode capacitor voltage multiplier is developed [4], where the overall voltage gain of the converter is decided by number of capacitors connected in circuit. a single-stage power factor corrected (PFC) AC-DC converter is presented. To increase efficiency of this converter, energy storage capacitor is [5]. Sliding mode control algorithm which increases efficiency and power factor [6] is developed for the boost three phase AC-DC converter. The converter performing input power factor correction using auxiliary winding of the main power transformer is developed and named as single stage AC-DC voltage fed full bridge converter [7]. Single stage input current shaping AC-DC converter is developed [8] for universal application which is based on an active clamp fly back forward topology and it requires boost inductor. An interleaved AC-DC converter is implemented [9] based on current tracking. A modulation strategy for a matrix AC-DC buck converter is discussed [10]. For power factor correction, a new bridgeless single stage half bridge AC-DC converter is developed to improve efficiency and power factor with minimum cost [11]. A three-phase unity-power-factor single-stage AC-DC converter is presented [12]. It is based on the interleaved fly back topology operated in DCM and increases overall efficiency and reduces harmonics [12]. With galvanic isolation, full bridge AC-DC converter operating at high frequency is presented. It performs sinusoidal input current wave shaping and output voltage regulation simultaneously without adding auxiliary transistors [13]. Single stage AC-DC converter is developed [14] to supply power for the plasma display panel This converter has achieved Low conduction loss, low switching losses and low line current harmonics. A control method is developed to control the input power of the PFC for the AC-DC converter which is used in electrical vehicle. In this control method, DC bus voltage of electrical vehicle is adaptively controlled based on the power demand from the battery charging curve of a battery [15]. To regulate the output voltage of an AC-DC Matrix Converter (MC), model predictive control methods are developed which efficiently controls the dc output voltage and the three-phase supply currents simultaneously [16]. The performance of two stage power conversion system with high frequency isolated AC-DC converter is analyzed [17].

The traditional single-stageAC-DC converters have following disadvantages.

1) Classical voltage-fed single-stage converters are pulse width-modulation (PWM) converters where large energy-storage capacitor is connected across the load. The basic role of this capacitor is to prevent overshoots and ringing effect which appears across the load voltage. Apart from that is also filters out the ac component.

2) These converters has very less power factor and less efficiency also. 
3) They also have higher input current harmonic content. The presented literature review is focused on study of single stage AC-DC converter with respect to parameters like modulation strategy, power factor correction, total harmonic distortion (THD) reduction and efficiency of converters. The system proposed in this paper consists of a single AC input and multiple DC outputs which overcomes some disadvantages of other systems.

We introduce novel structure of ac-dc converter which generate multiple outputs using single AC supply. The proposed converter overcome the disadvantages of classical systems.

\section{BASIC FULL CONTROLLED CONVERTER TOPOLOGY}

Fig. 1 shows thyristerized power circuitry of controlled bridge converter in which output voltage is controlled by the corresponding firing pulses with certain firing angle.

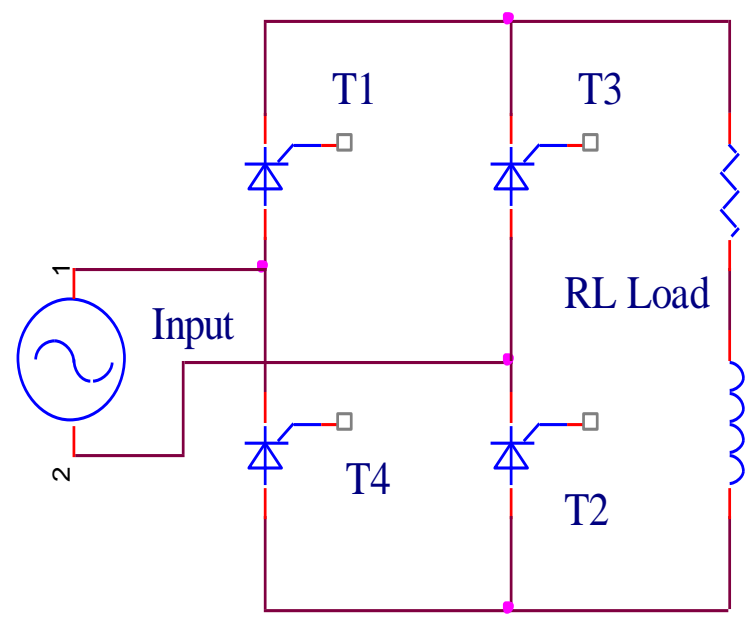

Fig. 1. Controlled Converter using Thyristor

Thyristors T1 and T2 are fired together for first half cycle of input while T3 and T4 are fired for second half cycle of input supply. But T1, T4 or T2, T3 cannot conduct simultaneously.

Fig. 2 shows transistorized power circuitry of controlled bridge converter. Transistors $\mathrm{T} 1$ and $\mathrm{T} 2$ are turn on together for first half cycle of input while Transistor T3 and T4 are turn on for second half cycle of input supply. Transistors T1, T4 or T2, T3 cannot conduct simultaneously. For switching of transistors, Pulse Width Modulation (PWM) technique is used in which output voltage is controlled by changing modulation index. In basic full controlled converter topology, only one load is connected and only positive DC voltage appears across load. But in proposed topology, even when multiple loads are connected, positive as well as negative DC output voltages appears across load.

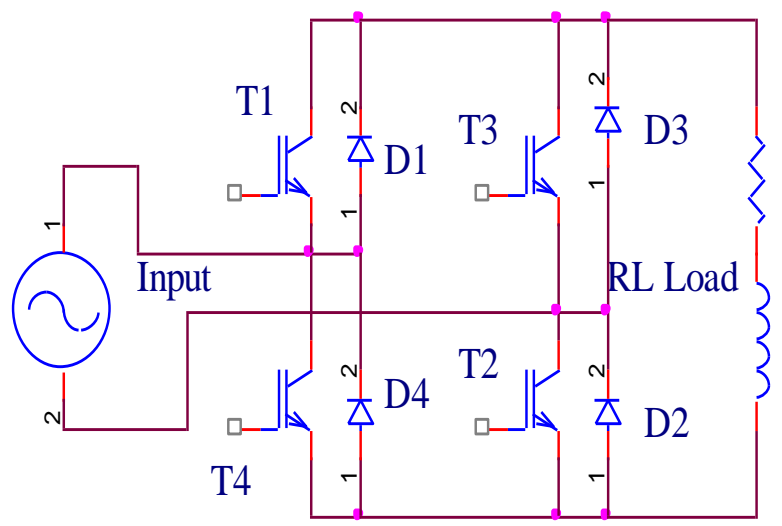

Fig. 2. Controlled Converter using Transistor (IGBT)

\section{PROPOSED MULTIMODE MATRIX AC-DC CONVERTER}

Fig. 3 shows structure of multimode matrix ac-dc converter. It contains eight switches for three loads. Desired output depends on switch condition whether it is ON or OFF.

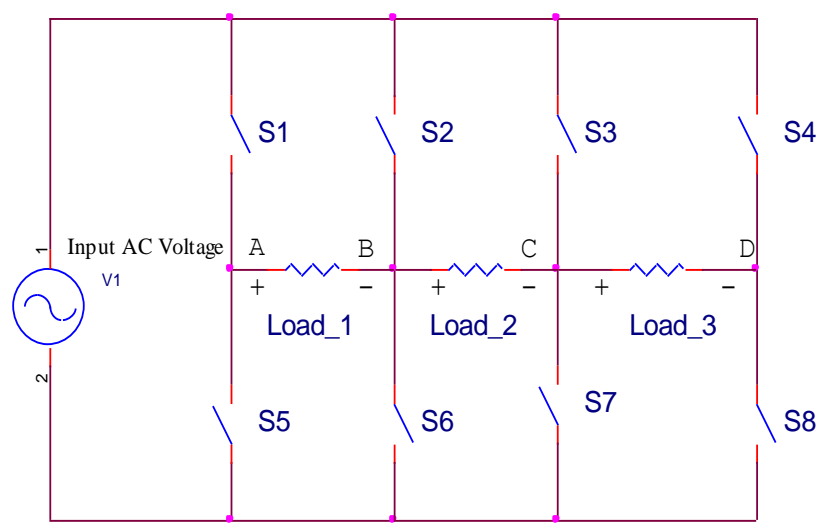

Fig. 3. Structure of Multimode matrix AC-DC converter

Single AC input supply is connected as input to the converter. It is a new concept presented in converter family. In Multimode matrix AC-DC converter, input is directly connected to output and one more column of two switches is added to build one more converter which has wide applications in various industries.

\section{PROPOSED MULTIMODE MATRIX AC-DC CONVERTER OPERATION}

The overall working operation of proposed multimode matrix AC-DC converter is divided into two states as below.

\section{A. State 1(0- $\pi)$}

In this state switches S1, S3, S6 and S8 are conducting simultaneously. A positive voltage appears across Load_1 which is connected between switch S1 and S6, as current flowing across it is positive to negative (A to B). Load_2 is connected between switch S3and S6 and current flowing across load_2 is negative to positive (C to B) which produces negative voltage across load_2. A positive voltage appears across Load_3 which is connected between switch S3 and S8, as current flowing across it is positive to negative(C to D). The equivalent circuit of state 1 is depicted in Fig.4. 


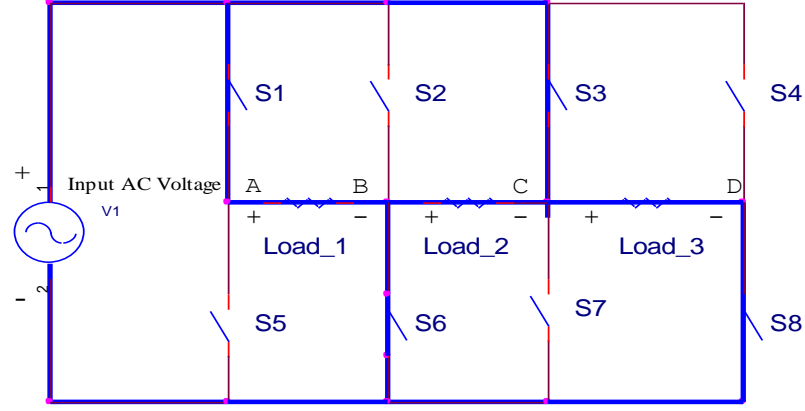

Fig. 4. Operation of Multiple Matrix AC-DC Converter in State 1

B. State $2(\pi-2 \pi)$ :

In this state switch S2, S4, S5 and S7 are conducting simultaneously. A positive voltage appears across Load_1 which is connected between switch S5 and S2, as current flowing across it is positive to negative (A to B). Load_2 is connected between switch S7and S2 and current flowing across load_2 is negative to positive (C to B) which produces negative voltage across load_2. A positive voltage appears across Load_3 which is connected between switch S7 and S4, as current flowing across it is positive to negative(C to D).

The equivalent circuit of state 2 is depicted in Figure 5.

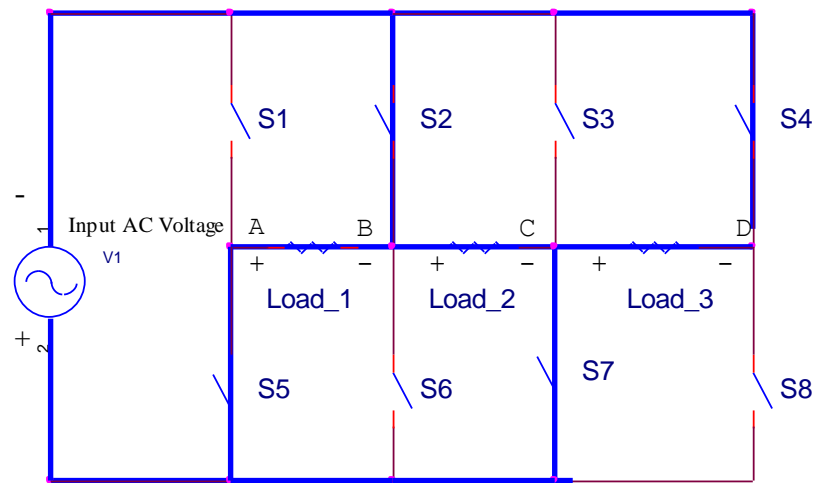

Fig. 5. Operation of Multimode matrix AC-DC Converter in State 2

\section{SWITCHING STRATEGIES}

A different switching arrangement is demanded by the multimode matrix AC-DC converter based on the desired multiple output voltages. A sinusoidal Pulse width modulation technique controls the output voltage of the converter. Operation of the proposed converter is divided in to two states.

Table 1 shows switching strategy of multiple matrix AC-DC converter in state 1 and state 2 .

Table 1 Switching State of Multiple Matrix AC-DC

\begin{tabular}{|c|c|c|c|c|c|c|c|c|c|c|c|c|}
\hline \multirow[b]{2}{*}{ State } & \multicolumn{8}{|c|}{ Switches } & \multirow[t]{2}{*}{ Input } & \multicolumn{3}{|c|}{ Output } \\
\hline & $\bar{n}$ & ผี & $\tilde{n}$ & जี & 너 & $\sqrt{4}$ & ñ & $\stackrel{\circ}{\xi}$ & & $\overbrace{}^{-1}$ & 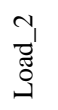 & 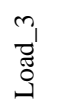 \\
\hline $\begin{array}{l}\text { State } \\
1(0- \\
\pi)\end{array}$ & 1 & 0 & 1 & 0 & 0 & 1 & 0 & 1 & $\mathrm{Vi+}$ & $\mathrm{Vo}^{+}$ & Vo- & $\mathrm{Vo}^{+}$ \\
\hline $\begin{array}{l}\text { State } \\
2(\pi \\
-2 \pi)\end{array}$ & 0 & 1 & 0 & 1 & 1 & 0 & 1 & 0 & Vi- & $\mathrm{Vo}^{+}$ & Vo- & $\mathrm{Vo}^{+}$ \\
\hline
\end{tabular}

State 1 Working :-

During state 1, total four switches namely S1, S3, S6 \& S8 are turned $\mathrm{ON}$ and the output voltage appears across all three loads as below.

$$
(S 1+S 3+S 6+S 8) V_{i+}=V_{0}^{+}+V_{0}^{-}+V_{0}^{+}
$$

\section{State 2 Working :-}

During state 2, as four switches namely S2, S4, S5 \& S7 are turned $\mathrm{ON}$, the output voltage appears across all three loads as below.

$$
(S 2+S 4+S 5+S 7) V_{i-}=V_{0}^{+}+V_{0}^{-}+V_{0}^{+}
$$

The input-output voltage relation for two intervals is given as,

$$
\begin{gathered}
V_{0}=V_{\text {in }} \\
{\left[\begin{array}{lll}
1 & 1 & 1 \\
1 & 1 & 1
\end{array}\right]\left[\begin{array}{l}
V_{0}^{+} \\
V_{0}^{-} \\
V_{0}^{+}
\end{array}\right]=\left[\begin{array}{l}
V_{i+} \\
V_{i-}
\end{array}\right]\left[\begin{array}{ll}
1 & 0 \\
0 & 1
\end{array}\right]}
\end{gathered}
$$

\section{First State Input interval (0- $\pi$ ):}

During first state, for positive half cycle oif input, output appears across Load_1 is positive, Load_2 is Negative and Load_3 is positive as below,

$$
V_{i+}=V_{0}^{+}+V_{0}^{-}+V_{0}^{+}
$$

Second State Input interval $(\pi-2 \pi)$ :

During second state, for negative half cycle of input, output appears across Load_1 is positive, Load_2 is Negative and Load_3 is positive as below,

$$
V_{i-}=V_{0}^{+}+V_{0}^{-}+V_{0}^{+}
$$

\section{ANALYSIS OF VOLTAGE AND CURRENT WAVEFORM OF PROPOSED CONVERTER}

As the DC voltage waveform is periodic over half cycle of the input voltage, it can be mathematically expressed as Fourier series as follows.

$$
V_{\text {output }}=V_{a v}+\sum_{n=1}^{\alpha}\left(V_{a n} \cos 2 \mathrm{n} \omega t+V_{b n} \sin 2 \mathrm{n} \omega \mathrm{t}\right)
$$

$$
\text { Where } \quad \operatorname{Vav}=\frac{1}{\pi} \int_{0}^{\pi} \text { vod } \omega t=\frac{2 \sqrt{2}}{\pi} \operatorname{Vin} \operatorname{Cos} \alpha,
$$$$
V_{\text {an }}=\frac{1}{\pi} \int_{\alpha}^{\pi+\alpha} v o \cos 2 \mathrm{n} \omega t d \omega
$$

$$
=\frac{2 \sqrt{2}}{\pi} \operatorname{Vin}\left(\frac{\operatorname{Cos}(2 n+1) \alpha}{2 n+1}-\frac{\operatorname{Cos}(2 n-1) \alpha}{2 n-1}\right)
$$

$V_{b n}=\frac{1}{\pi} \int_{0}^{\pi} v o \sin 2 n \omega t d \omega t=\frac{2 \sqrt{2}}{\pi} V i\left(\frac{\sin (2 n+1) \alpha}{2 n+1}-\frac{\sin (2 n-1 \alpha)}{2 n-1}\right)$

Output voltage rms value of $\mathrm{n}^{\text {th }}$ harmonic is given as,

$$
V_{\text {orms }}=\frac{1}{\sqrt{2}} \sqrt{{V_{a n}{ }^{2}+V_{b n}{ }^{2}}^{2}}
$$

The positive DC output voltage appearing across Load _1 and Load_3 can be mathematically expressed as, 


\section{Implementation of Single Phase Multimode Matrix AC-DC Converter}

$$
+V_{\text {Orms }}=\sqrt{\frac{1}{\pi} \int_{\alpha}^{\pi+\alpha} V_{o}^{2} d \omega t}=V i
$$

The voltage and current waveform of the converter are shown in Fig. 6

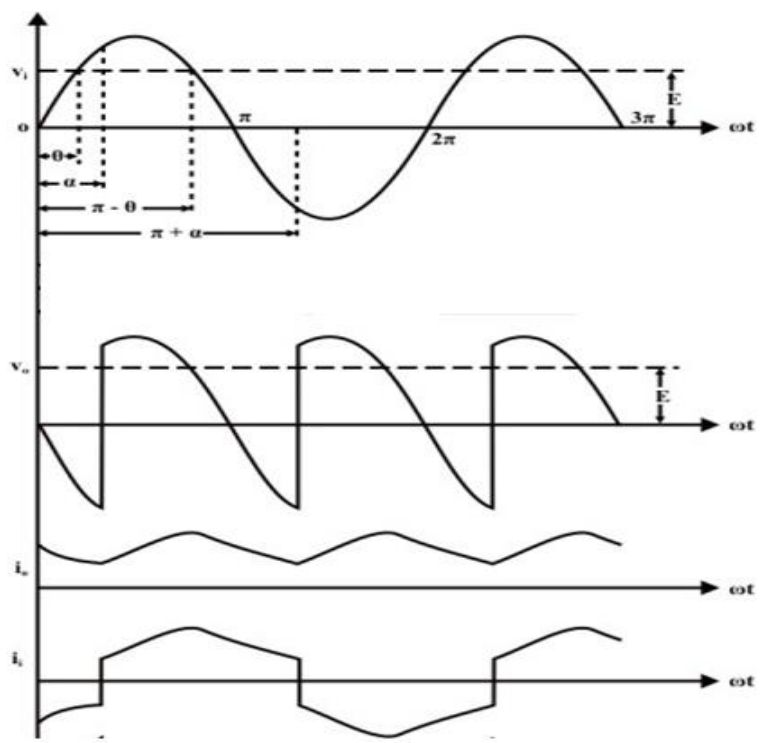

Fig. 6. Waveforms of voltage and current of converter

The output voltage appearing across Load_2 (negative DC output) is mathematically expressed as,

$$
\text { -Vorms }=\sqrt{\frac{1}{\pi} \int_{\alpha}^{\pi+\alpha} V_{o}^{2} d \omega t}=V i
$$

The output current Io waveform is periodic over an interval o- $\pi$ and it is expressed over interval of length $\alpha<\omega t<\pi+$ $\alpha$

$$
\mathrm{L} \frac{d i o}{d t}+\mathrm{Rio}+\mathrm{E}=\sqrt{2} \mathrm{Vi} \sin \omega t
$$

The general solution of equation is given by,

$$
i_{0}=I e^{-\frac{(\omega t-\alpha)}{i a m p}}+\frac{\sqrt{2} \mathrm{Vi}}{Z}\left[\sin (\omega t-\sigma)-\frac{\sin \theta}{\cos \sigma}\right]
$$

Where

$$
\mathrm{Z}=\sqrt{\mathrm{R}^{2}+\omega^{2}} L^{2}, \quad \tan \sigma=\frac{\omega L}{R},
$$

$\mathrm{E}==\sqrt{2} \mathrm{Vi} \sin \theta, \mathrm{R}=\mathrm{Z} \cos \sigma$ and $i_{0}$ is periodic over the interval of $\alpha$ and $\pi+\alpha$.

\section{SIMULATION MODEL OF MULTIMODE MATRIX AC-DC CONVERTER}

Simulation model is developed in Matlab-Simulink with following specifications.

\begin{tabular}{|l|l|}
\hline Input Voltage & $100 \mathrm{~V}$ \\
\hline R Load & $15 \Omega$ \\
\hline RL Load & $\mathrm{R}=15.44 \Omega$ \\
& $\mathrm{L}=1.2 \mathrm{mH}$ \\
\hline
\end{tabular}

SPWM Technique is used for Controlling Switches for the Operation of multiple AC-AC converter. The simulation model describing the multiple AC-AC converter is shown in Figure.7.

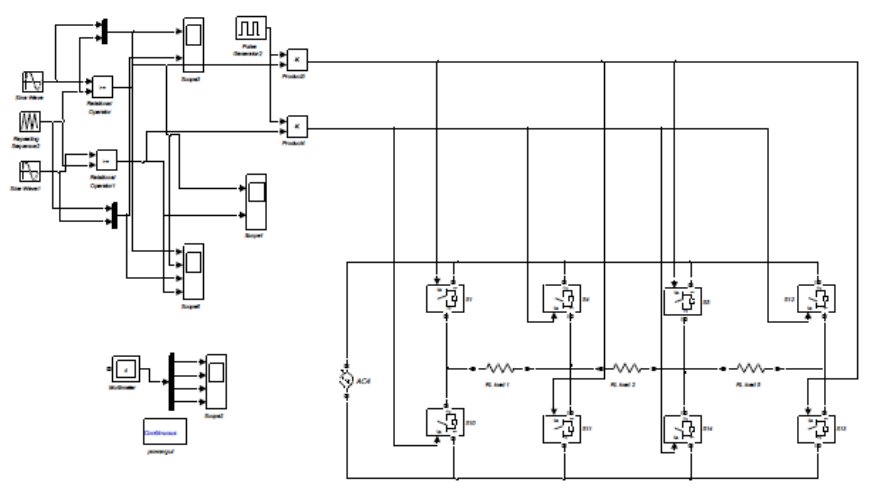

Fig. 7. Simulation Model of Multi_out AC-DC converter

Simulation model of multimode matrix converter is shown in Fig.7. The Switching algorithm for desired output of multimode matrix AC-DC converter is developed in MATLAB SIMULINK software. Sine wave blocks are produced and Vrefl and Vref2 (Vm) is compared with triangular Wave using relational operator block. The repeating sequence block is used to generate triangular carrier signal 'Vc'. Output of Relational operator block is SPWM signal which is multiplied with square wave.

Pulse generator block generates square wave. The resultant of multiply block is final switching pattern which is used to turn ON and turn OFF switches. By changing modulation index of sine wave block, the magnitude of output is changed.

\section{POWER CIRCUIT OF MULTIPLE MATRIX AC-DC CONVERTER}

A schematic diagram of multimode matrix AC-DC converter with inductive load is shown in Fig 8. The proposed multimode AC-DC converter generates a fully controlled output voltage across load and IGBTs are used as power devices. IGBTs S1, S3, S6 and S8 are turned ON for positive half cycle while S2, S4, S5 and S7 are turned ON for negative half cycle. From the Fig 8., it is clear that for any load current conduction, at least two transistors from each group that is from top and bottom (S1, S3, S6 \&S8) must conduct to $0-\pi$ (positive half cycle) and two transistors from each group of the top and bottom (S2, S4, S5 and S7) must conduct to $\pi-2 \pi$ (negative half cycle). It is important to note that neither S1, S2, S3 and S4 nor S5, S6, S7 and S8 conduct simultaneously.

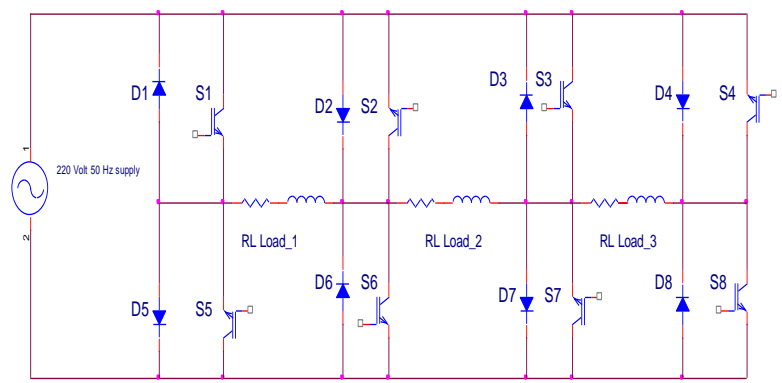

Fig. 8. Power circuit of Multi_out AC-DC converter

Blue Eyes Intelligence Engineering \& Sciences Publication 


\section{CONTROL CIRCUIT}

Figure 9 shows schematics of control circuitry of multimode matrix AC-DC converter. The control circuit is consist of sensing transformer, two Op_Amps, and AND Gates.

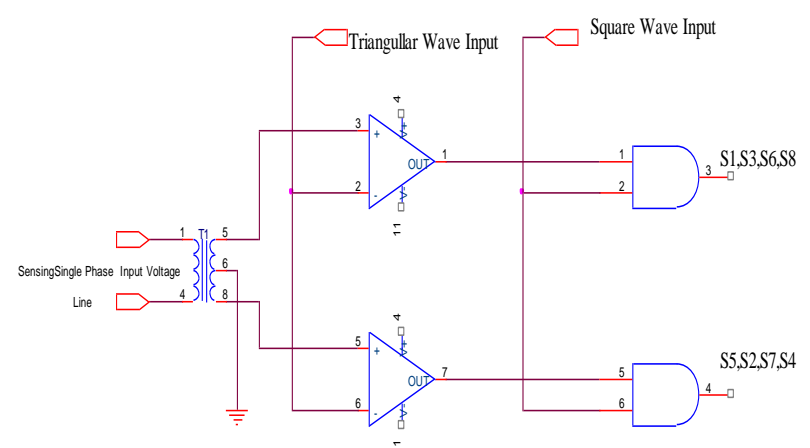

Fig. 9. Multimode AC-DC converter's control circuitry

Op-Amp based comparator is designed to compare Sine wave with triangular wave and it generates sinusoidal Pulse Width Modulation (SPWM) signal. By changing modulation index of sine wave block, the magnitude of load voltage is controlled. SPWM outputs are multiplied with square wave using AND gate. AND gate outputs are connected to IGBT. The frequency of output voltage across load is controlled by square wave. In the practical circuitry, Op_Amp IC LM 339 and AND gate IC 4081 are used. Transformer is used for input reference signal.

\section{RESULTS AND DISCUSSION}

The proposed topology of multimode matrix AC-DC converter is initially simulated and later test experimentally

\section{A. Simulated results}

Simulation model is used to study the concept of Multimode matrix AC-DC Converter. Fig. 10 shows simulated SPWM output across both Op_Amps alongwith sine wave and triangular wave. The simulated output across Multiple Loads without Filter and with filter is presented in Fig. 11 and Fig. 12 respectively.

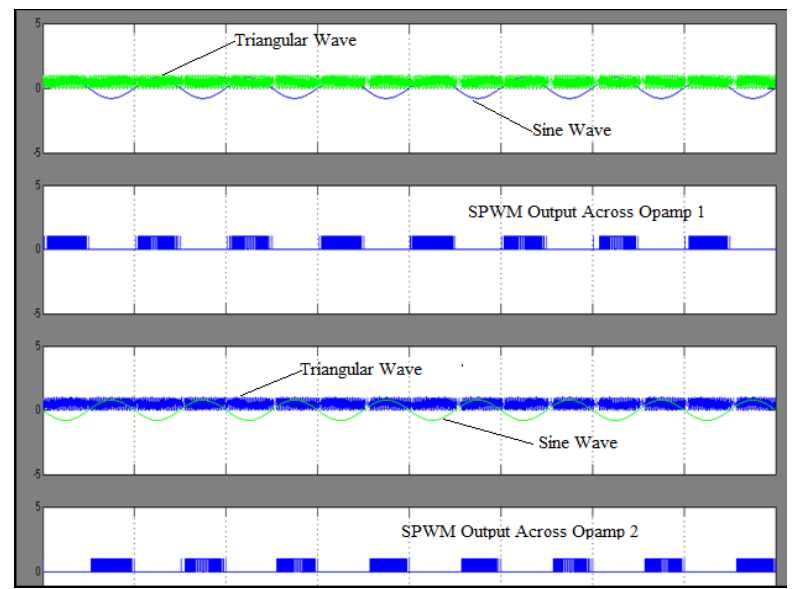

Fig 10. Simulated Sinusoidal Pulse Width Modulation (SPWM) output
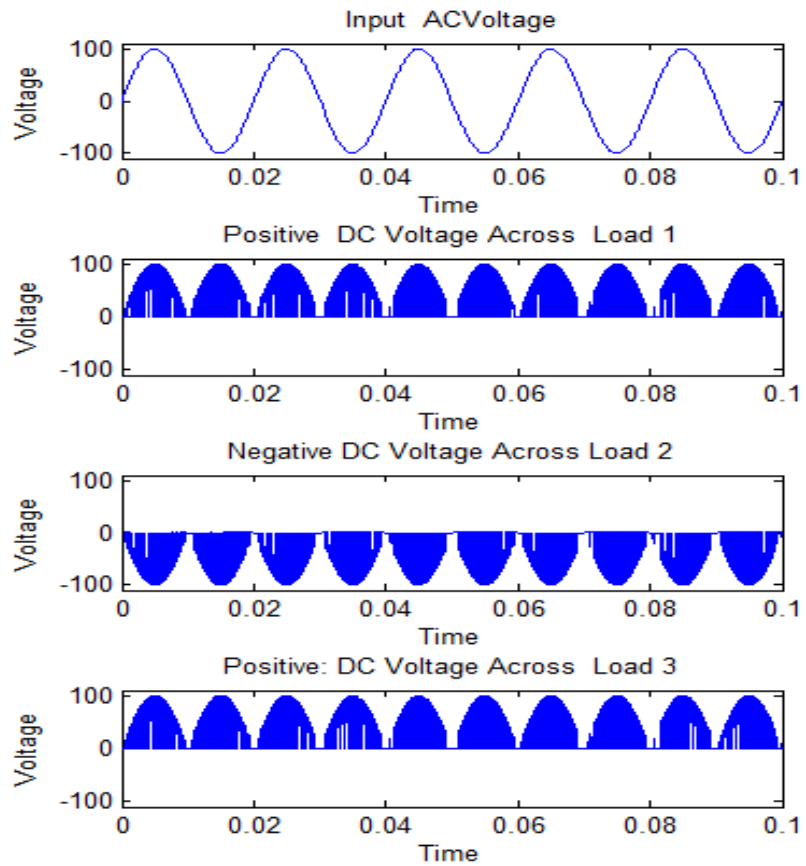

Fig11. Simulated output across Multiple Loads without Filter
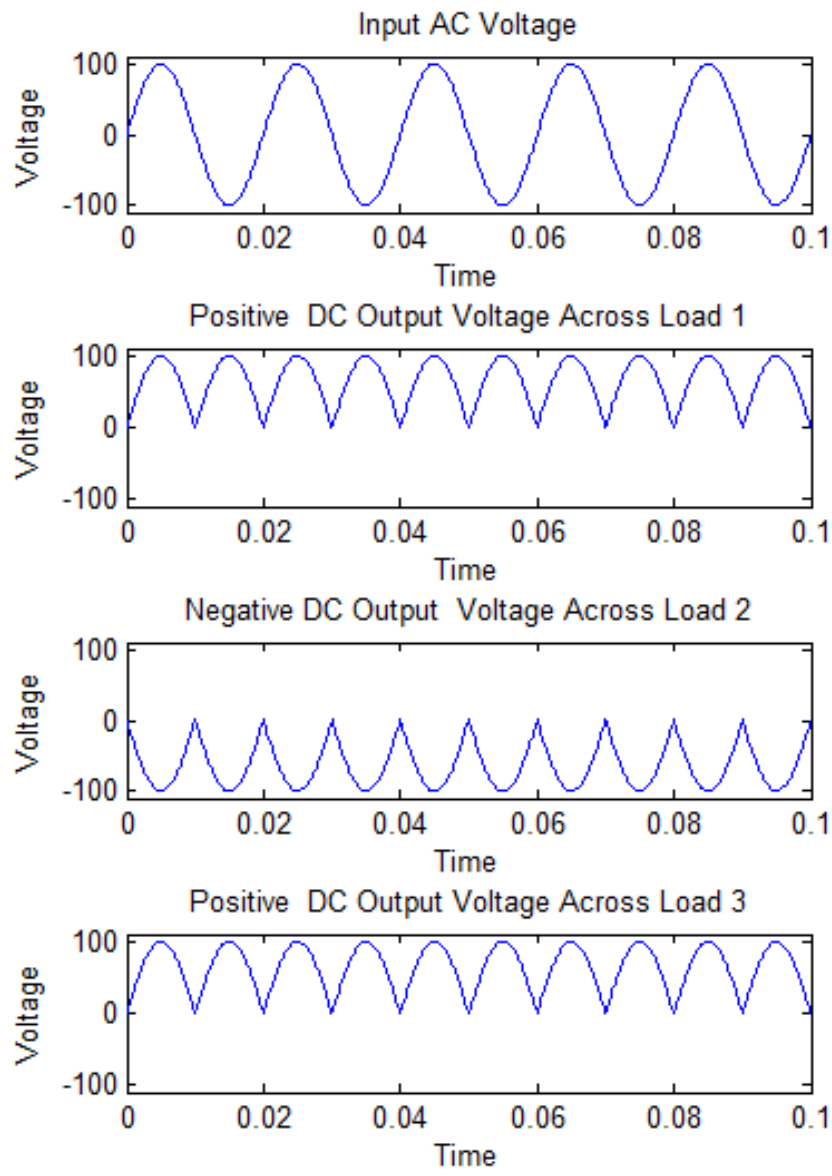

Fig 12 Simulated output across Multiple Loads with

Filter 


\section{Implementation of Single Phase Multimode Matrix AC-DC Converter}

\section{B. Experimental Results}

The concept of multimode matrix AC-DC converter has been verified experimentally in the laboratory. It is observed that there is best agreement between the experimental and simulated results.

Fig.13 shows experimental Sinusoidal Pulse width Modulation (SPWM) Output. The experimental DC Output Voltage across Load_1, Load_2 and Load_3 without filter is presented in Fig. 14, 15, and 16 respectively. It is clear that high frequency PWM signal appears across all three loads. The experimental DC Output Voltage across Load_1, Load_2and Load_3 with filter is presented in Fig. 17, 18, and 19 respectively. It is clear from these figures that there is no distortion across the load and thus harmonics are also reduced.

Experimental results of input and output voltage waveform for resistive load is shown in Fig 20. It is observed that voltage and current waveforms are in phase and there is unity power factor for resistive load.

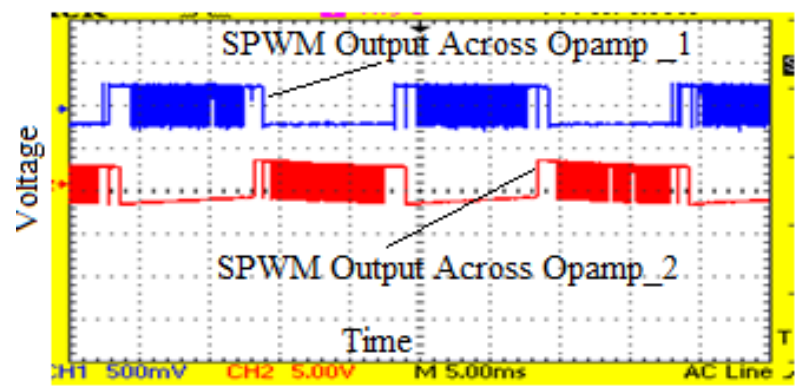

Fig 13 Experimental Sinusoidal Pulse width Modulation (SPWM) output

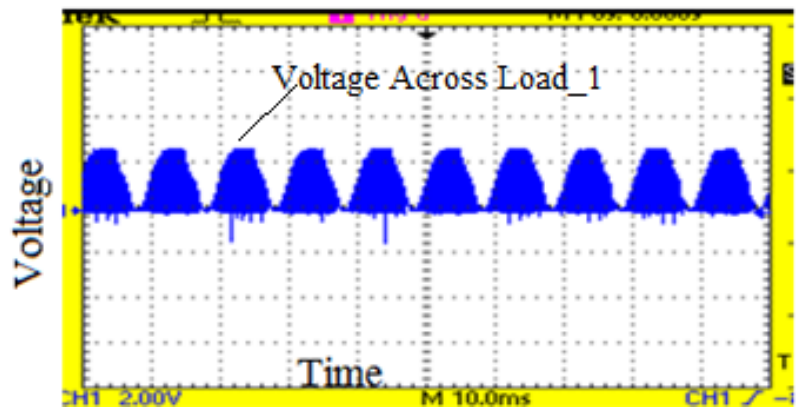

Fig. 14 Experimental DC Output Voltage across Load_1 without filter

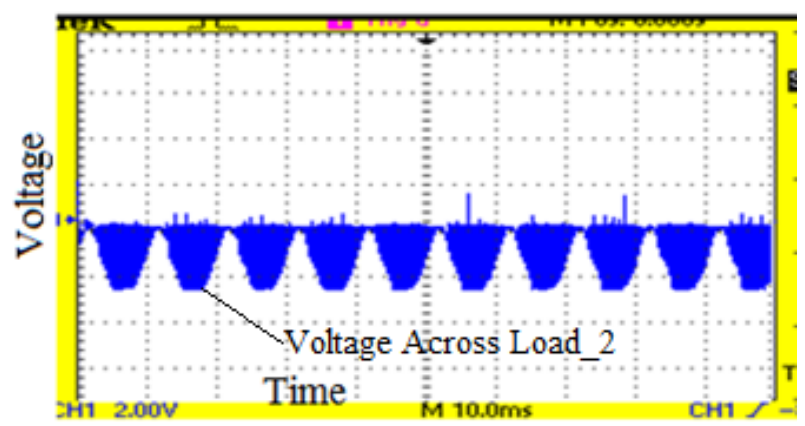

Fig. 15 Experimental DC Output Voltage across Load_2 without filter

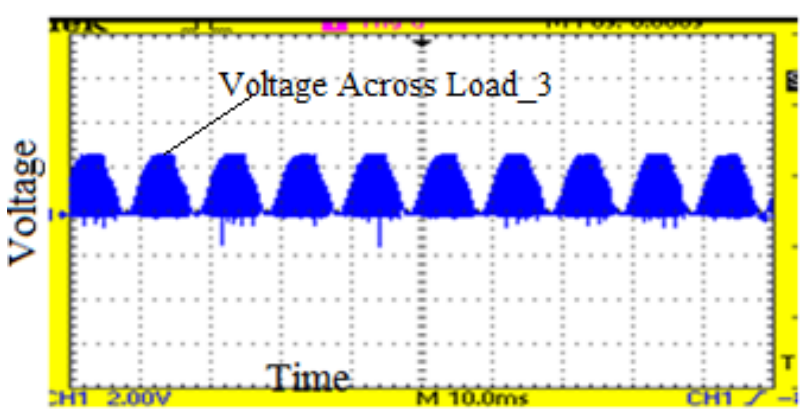

Fig. 16 Experimental DC Output Voltage across Load_3 without filter

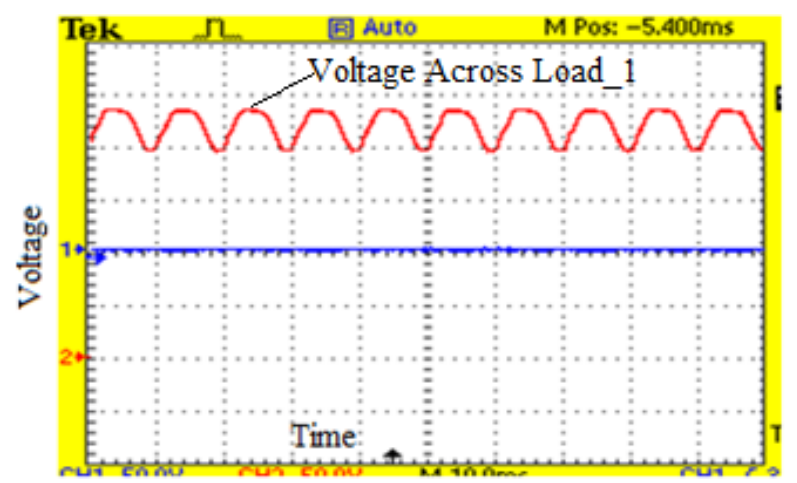

Fig. 17 Experimental DC Output Voltage across Load_1 with filter

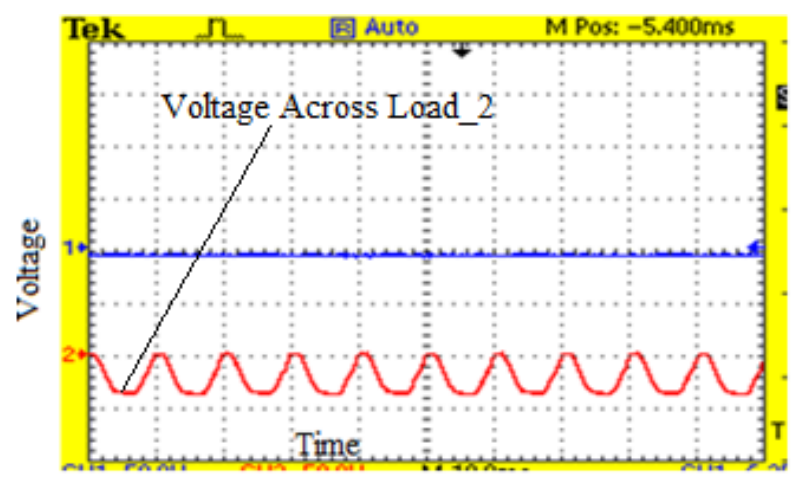

Fig. 18 Experimental DC Output Voltage across Load_2 with filter

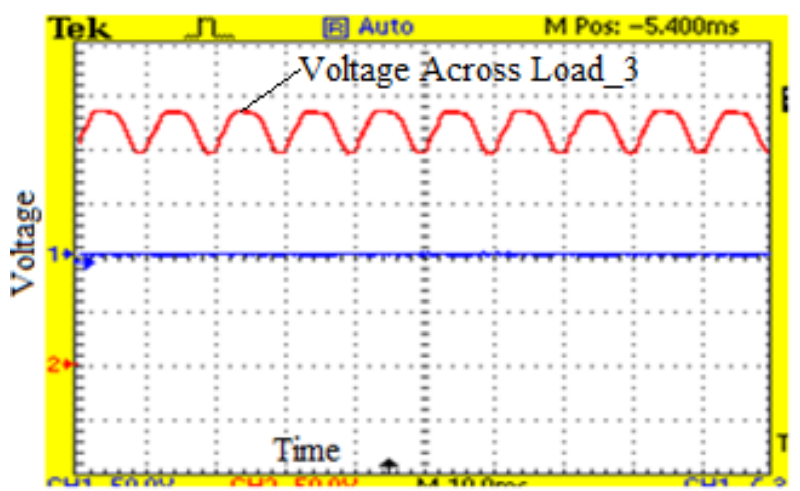

Fig. 19 Experimental DC Output Voltage across Load_3 with filter 


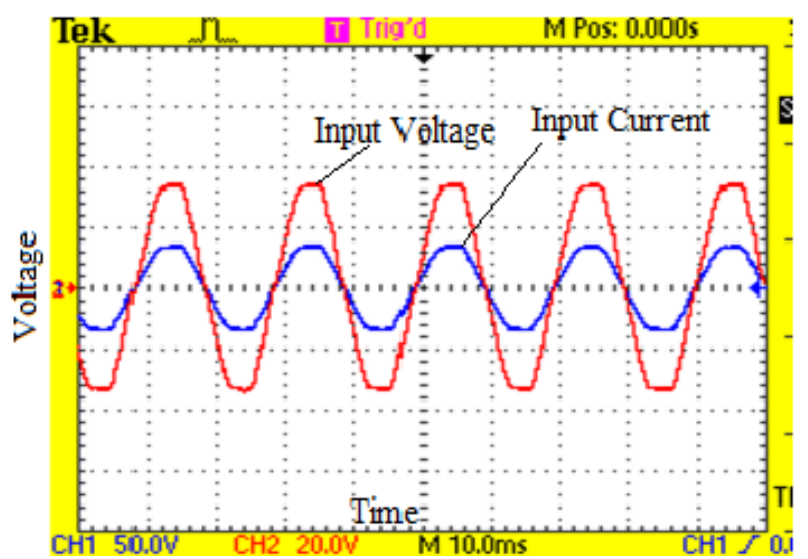

Fig 20 Experimental Input voltage and current waveforms for resistive load

\section{COMPARISON OF TRADITIONAL TOPOLOGY}

The proposed multimode matrix converter can be compared with traditional Full wave bridge converter. The multimode converter gives multiple outputs while full wave bridge converter gives only one load at a time. The multimode matrix converter operates in four quadrants and gives positive as well as negative DC voltage across the load.

Full wave AC-DC converter operates in two quadrants and gives only positive DC voltage across the load.

Without any DC link capacitor/inductor, input is directly connected to output in the proposed multimode matrix converter and there is reduction in the harmonic distortion.

The Full Wave bridge converte requires more power devices as compared to developed multimode converter. In this context, the comparative study of traditiional and proposed topology is tabulated in Table 2.

Table 2 Comparative study of traditional and proposed topology.

\begin{tabular}{|c|l|l|}
\hline $\begin{array}{c}\text { No. of } \\
\text { Outputs }\end{array}$ & $\begin{array}{l}\text { Full wave Bridge } \\
\text { Converter }\end{array}$ & $\begin{array}{l}\text { Single Phase } \\
\text { Multimode AC-DC } \\
\text { Converter }\end{array}$ \\
\cline { 2 - 3 } & $\begin{array}{l}\text { No. of Power } \\
\text { Devices required }\end{array}$ & $\begin{array}{l}\text { No. of Power } \\
\text { Devices required }\end{array}$ \\
\hline 1 & 4 & 4 \\
\hline 2 & 8 & 6 \\
\hline 3 & 12 & 8 \\
\hline 4 & 16 & 10 \\
\hline
\end{tabular}

\section{APPLICATIONS OF MULTIMODE MATRIX CONVERTER}

There are numerous application in power industry of this multimode matrix converter; but only few are listed here. The proposed multimode matrix converter can be used for battery charging applications. Using this converter multiple batteries can be charged simultaneously. It is also useful to drive DC motors. It is applicable in the process industry to drive different DC motors simultaneously. It reduces the cost of DC drive system because one system drives multiple DC motors. This converter is used as power supply for different circuits.

\section{CONCLUSION}

A multimode matrix topology for AC-DC converter is proposed which generates multiple DC outputs from single AC input. In the proposed converter, variable DC voltage appears across multiple loads. To synthesize desired output of multiple converter, SPWM technique is used. Control scheme is implemented with passive loads. Simulation results shows good agreement with practical results.

The proposed multimode AC-DC converter can be used in industrial applications with variable voltage. It could be first choice for high speed, low/high applications such as traction, DC motor drives, and HVDC systems.

\section{REFERENCES}

1. Huai Wei, Issa Batarseh, Guangyong Zhu, and Peter Kornetzky, "Single Switch AC-DC converter with Power Factor Correction," in the IEEE Transaction on Power Electronics Vol.15,No.3,May 2000, pp. 421-430.

2. Ivan Eidt Colling,Ivo Barbi, "Reversible Unity Power Factor Step up-Step Down AC-DC Converter Controlled by Sliding Mode," in the IEEE Transaction on Power Electronics Vol.16,No.2,March 2001, pp. 223-230.

3. Gerry Moschopoulos, "A Simple AC-DC PWM Full Bridge Converter with Integrated Power Factor Correction," in the IEEE Transaction on Industrial Electronics Vol.50, No.6, December 2003, pp. 1290-1297.

4. A.Shenkman, Y.Berkovich and B.Axelrod, "Novel AC-DC and DC-DC converter With Diode Capacitor Multiplier," in the IEEE Transaction on Aerospace and Electronics System. Vol.40, No.4, Octoberr 2004, pp. 1280-1293.

5. Antonio,Lazaro,Andres Barrado,Marina Sanz, Vicente Salas,and Emilio Olias, "New Power Factor Correction AC-DC converter with Reduduced Storage Capacitor Voltage, "in the IEEE Transaction on Industrial Electronics Vol.54,No1,February 2007, pp. 384-397.

6. Yuri Shtessel,Simion Baev,and Haik Biglari, "Unity Power Factor Control in Three Phase AC-DC Boost Converter Using Sliding Modes, in the IEEE Transaction on Industrial Electronics Vol.55,No11,November 2008, pp. 3874-3882.

7. Pritam Das,Shumin Li, and Gerry Moschopoulos, "An improved AC-DC Single Stage Full Bridge Converter With Reduced DC Bus Voltage," in the IEEE Transaction on Industrial Electronics Vol.56,No.12,December 2009, pp. 4882-4892.

8. Yen-Ming Liu,Lon-Kou Chang, "Single Stage Soft Switching AC-DC converter With Input Current Shaping For Universal Line Applications," in the IEEE Transaction on Industrial Electronics Vol.56, No.2, February 2009, pp. 467-481.

9. K.I.Hwu, Y.T.Yau, "An Interleaved AC-DC converter Based On Current Tracking," in the IEEE Transaction on Industrial Electronics Vol.56, No.5, May 2009, pp. 1456-1463.

10. Miro Milanovic, Primoz Slibar, "IDF-Correction -Based PWM Algorithm for Three Phase AC-DC Buck Converter," ," in the IEEE Transaction on Industrial Electronics Vol.58, No.8, August 2011, pp. 3308-3316.

11. Woo-Young Choi, Joo-Seung Yoo, “A Bridgeless Single-Stage HalfBridge AC-DC converte," in the IEEE Transaction on Power Electronics Vol.26, No.12, December 2011, pp. 3884-3895.

12. Bunyamin Tamyurek,David A.Torrey, "A three Phase Unity Power Factor single Sytage AC-DC converter based on An interleaved Flyback topology," in the IEEE Transaction on Power Electronics Vol.26,No.1,January 2011, pp308-311.

13. Hugo Santos Ribeiro,Beatriz Vieira Borges, "New optimized full bridge Single Stage AC-DC converters," in the IEEE Transaction on Industrial Electronics Vol.58, No.6, June 2011, pp. 2397-2409.

14. Woo-Young Choi,Jae-Yeon Choi, "A Novel Single-Stage AC-DC converter to supply Sustain Power for Plasma display panels," in the Journal of Display Technology,Vol.7 ,No.9 September,2011 pp. 494-502.

15. Majid Pahlevaninezhad,Pritam Das,Josef Drobink,Praveen K. Jain and Alireza Bakhshai, "A New Control Approach Based on 


\section{Implementation of Single Phase Multimode Matrix AC-DC Converter}

The differential Flatness Theory for an AC-DC converter used in Electric Vehicles," in the IEEE Transaction on Power Electronics Vol.27,No.4,April 2012, pp2085-2103.

16. Mustafa Gokdag Ozan Gulbudak,"' Model Predictive Control of AC-DC Matrix Converter with Unity Input Power Factor", IEEE 12th International Conference on Compatibility, Power Electronics and Power Engineering (CPE-POWERENG 2018) Doha Quatar April 2018 pp.1-5

17. Zarchi Linn,Koji Shigeuchi,Yukihiko and Yukihiko Sato,"Performance Analysis of High Frequency Isolated AC-DC Converter Based on Matrix Converter", 15th International Conference on Electrical engineering/Electronics, Computer, Telecommunications and Information Technology (ECTI-CON) Chiang Rai, Thailand, July 2018 pp.286-289.

\section{AUTHORS PROFILE}

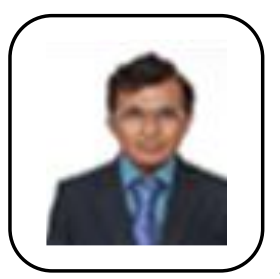

Sanjay Mohite received the B.E in Electronics Engineering from Pune University in 2002. and M.E. Electronics from Dr. Babasaheb Ambedkar Marathwada University, Aurangabad, in 2007, and Ph.D. degree from Symbiosis International University Pune, in 2015.

From June 93 to September 2004, he ran own electronic company in the field of converters. He is currently a Professor with the Jayawantrao Sawant College of Engineering Pune. He holds one China patents, one European Patent and two Indian Patents. His research interests include high frequency converters applications and digital control techniques for the Electric Vehicle (EV) charger and Developing products for Industry 4.0 Generation.

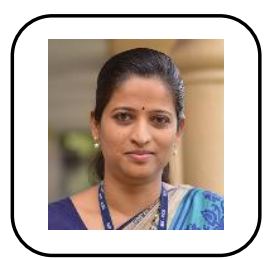

Suchitra Khoje graduated in Electronics Engineering from Shivaji University in 2000, post graduated in M. E. (Digital Systems) from Pune University, Pune in 2009 and awarded $\mathrm{PhD}$ from Symbiosis International University in 2015.

Her research interests are in the area of signal processing, machine learning, power electronics and embedded systems. She has 18 years of experience which includes 15 years teaching, 2 years research and one year in industry. She is member of IEEE and has Lifetime membership of ISTE. She has more than twenty research papers on her credit. 